\title{
The Effect of Iron Deficiency on Respiration and Energy-coupling in Escherichia coli
}

\author{
By D. J. RAINNIE AND P. D. BRAGG \\ Department of Biochemistry, University of British Columbia, \\ Vancouver, B.C., Canada
}

(Received 21 December 1972; revised 2 March 1973)

SUMMARY

\begin{abstract}
Growth and respiration were affected when iron became limiting in batch cultures of Escherichia coli growing in succinate medium. Decrease occurred in the efficiency with which succinate was converted to bacterial mass, in the respiratory-control ratio, in the extent of stimulation of respiration by silver ions, and in the levels of non-haem iron, cytochrome $b_{1}$, and NADH and succinate oxidase activities. On addition of ferric citrate to the iron-limited cultures the above components returned at different rates to the levels found in iron-sufficient bacteria. The efficiency of conversion of succinate to bacterial mass, the respiratory-control ratio, and the concentration of non-haem iron recovered more rapidly than did the level of cytochrome $b_{1}$ and the oxidase activities. It is postulated that non-haem iron is involved in respiratory chain-linked energy production.
\end{abstract}

\section{INTRODUCTION}

Iron limitation during the growth of bacteria results in decreased activities of a number of enzymes and enzyme systems associated with the respiratory chain, for example the NADH-nitrate reductases of Micrococcus denitrificans (Fewson \& Nicholas, 1961 $a$ ), Pseudomonas denitrificans (Radcliffe \& Nicholas, 1970), and $P$. aeruginosa (Fewson \& Nicholas, I96I $b$ ); the NADH-cytochrome $c$ reductase of Mycobacterium smegmatis (Fewson \& Nicholas, I96I $b$ ); the succinate dehydrogenase activities of $M$. smegmatis and Corynebacterium diphtheriae (Winder \& O'Hara, 1964; Righelato, 1969).

In Candida utilis iron limitation, besides giving lower levels of cytochromes (Ohnishi, Schleyer \& Chance, 1969; Clegg \& Garland, 197I), also results in a loss of energy-coupling at site I (Clegg \& Garland, I97I). The loss of energy-coupling was shown in a subcellular system both by a decreased $\mathrm{P}: \mathrm{O}$ value and, more specifically, by the loss of the energydependent reduction of NAD linked to the oxidation of glycerol-3-phosphate. The latter system does not require the participation of ATP which suggests that iron is involved in energy-coupling at a stage before the formation of ATP. In contrast to the results with C. utilis, oxidative phosphorylation in respiratory particles from Micrococcus denitrificans is not affected by iron deficiency, although the electron paramagnetic resonance signal associated with respiratory chain-linked non-haem iron disappears (Imai, Asano \& Sato, 1968). Thus, it is not clear whether non-haem iron, as well as being a component of the respiratory chain, has a role in energy-coupling in this organism.

The present study with Escherichia coli was undertaken because of the limited and conflicting information available on the role of iron in the respiratory chain, and in energycoupling linked to the respiratory chain, in bacterial systems. 
Cell-free systems from bacteria generally show much lower P:O values than those observed in tightly coupled mitochondria (Gel'man, Lukoyanova \& Ostrovskii, I967). Moreover, it was only recently that ADP-ATP-mediated respiratory control has been demonstrated in bacterial cell-free systems (John \& Hamilton, I97I; Jones, Ackrell \& Erickson, 197I). Thus, cell-free systems were considered to be unsuitable for our studies. However, $P: O$ values obtained with intact bacteria also may not accurately reflect the ability of the bacterium to generate energy via the respiratory chain. Energy-utilizing reactions, other than ATP formation, could compete for the respiratory chain-generated high energy states or intermediates (Harold, 1972). In mitochondria that respiration which can be stimulated by ADP and which results in its conversion to ATP can also be stimulated by uncoupling agents. This has also been shown with respiratory particles of Micrococcus denitrificans (John \& Hamilton, 197I). The stimulation of respiration by an uncoupling agent is probably due to the dissipation of a high energy state or an intermediate (Harold, 1972) and could be used as an indicator of the presence of the high energy state whether or not this could be converted to ATP. We used this technique to study the effect on energy coupling in intact bacteria of progressive iron limitation such as occurs during growth in an iron-limited batch culture. The recovery process was also examined after addition of iron to the deficient cells. The results, presented in this paper, suggest that limitation of iron in cultures of Escherichia coli may result in the impairment of energy-coupling as well as a reduced synthesis of the iron-containing enzymes of the respiratory chain.

\section{METHODS}

Chemicals. Tris (hydroxymethyl) aminomethane (tris) and ammonium sulphate were of ultra pure grade obtained from Schwarz-Mann, Orangeburg, New York, U.S.A. o-Phenanthroline was obtained from Fisher Scientific Company, Fair Lawn, New Jersey, U.S.A., and 2,4-dibromophenol was supplied by Eastman Organic Chemicals, Rochester, New York, U.S.A. All other chemicals were of reagent grade purity.

Culture of cells and preparation of extracts. Most of the study was on Escherichia coli strain 482 (culture collection of the National Research Council of Canada). Also used were $E$. coli B (ATCC II 303), and E. coli B-SGI (R. J. Harvey, Burroughs Wellcome Co.), and a mutant of $E$. coli B, which cannot synthesize glycogen, isolated by J. Preiss (University of California, Davis).

Batch culture was used in these experiments since the effects of very low levels of iron could be studied by allowing the bacteria to deplete the iron in the medium. The electrodes were separated from the bulk of the culture medium because vigorous aeration resulted in unstable measurements. The culture in the electrode vessel could be at a lower oxygen tension than the main vessel. However, as there was a dead space of only $2 \mathrm{ml}$ between the main culture and the electrode chamber, and since the liquid in the chamber was being continually renewed at the rate of once ever $15 \mathrm{~s}$, it is likely that the physical conditions in the electrode vessel would not be greatly different from those in the main culture vessel. To check this point, the circulation of a mid-exponential phase culture between the two vessels was stopped. In I $5 \mathrm{~s}$ the oxygen tension in the electrode vessel dropped by $5 \%$. This would probably be the maximum difference to be expected between the main culture and the electrode vessel.

The bacteria were grown on a minimal salts medium of the following composition: $0.7 \% \mathrm{~K}_{2} \mathrm{HPO}_{4}, 0.3 \% \mathrm{KH}_{2} \mathrm{PO}_{4}, 0.3 \%\left(\mathrm{NH}_{4}\right)_{2} \mathrm{SO}_{4}, 0.02 \% \mathrm{MgSO}_{4} .7 \mathrm{H}_{2} \mathrm{O}$ with either $1.38 \%$ $\mathrm{Na}_{2}$ succinate. $6 \mathrm{H}_{2} \mathrm{O}$ or $0.4 \%$ glucose as the carbon source. The concentration of iron in this 
medium was decreased by filtration through a $0.45 \mu \mathrm{m}$ pore size MF-Millipore filter. Ferric citrate was added, before inoculation, or during growth, to yield a concentration of $6 \mu \mathrm{M}$ in the culture medium. The culture was grown at $37^{\circ} \mathrm{C}$ in a brown glass culture jar $(2500 \mathrm{ml}$ capacity). Growth was initiated by inoculation of 1500 to I $800 \mathrm{ml}$ of the above medium with $100 \mathrm{ml}$ of a $\mathrm{I} 2 \mathrm{~h}$ culture. The culture was continuously circulated through a second, sealed vessel ( $50 \mathrm{ml}$ capacity) at a rate of 200 to $300 \mathrm{ml} / \mathrm{min}$ by means of a pump (GormanRupp Industries, Bellville, Ohio, U.S.A.). This vessel contained a Clark-type oxygen electrode (Yellow Springs Instrument Co., Yellow Springs, Ohio, U.S.A., Model 5533), combination glass pH electrode (Fisher-Scientific Co., Pittsburgh, Pennsylvania, U.S.A., Model I3-639-90), a platinum redox electrode (Beckman Instruments, Palo Alto, California, U.S.A., Model 39273), and a small Teflon-coated magnetic stirring bar, and was supported on a magnetic stirrer. The $\mathrm{Ag}^{+} / \mathrm{AgCl}$ couple of the $\mathrm{pH}$ electrode was used also as the reference electrode for the measurement of redox potential. The $\mathrm{pH}$ value, oxygen content, and oxidation-reduction potential of the culture were determined at intervals of 15 or 30 min depending on the rapidity of change in these parameters. Growth was measured by following the absorbance of the culture at $420 \mathrm{~nm}$ in cuvettes with a $\mathrm{I} \mathrm{cm}$ path length. The culture was maintained at $\mathrm{pH} 7 \cdot 00 \pm 0.15$ by the addition of $5 \mathrm{~N}-\mathrm{HCl}$ via a peristaltic pump. The culture was aerated through a sintered glass sparger (Kimax ${ }_{2} 2 \mathrm{C}$ ) with an air flow rate of $4.4 \mathrm{l} / \mathrm{min} / 1$ of culture.

Bacteria, harvested at the intervals indicated in the description of the individual experiments, were sedimented at $2{ }^{\circ} \mathrm{C}$ by centrifuging the suspensions at $\mathrm{I} 2000 \mathrm{~g}$ for $10 \mathrm{~min}$, washed twice by sedimentation from O. I M-tris- $\mathrm{HCl}$ buffer, $\mathrm{pH} 7 \cdot 5$, at $2{ }^{\circ} \mathrm{C}$, finally suspended in the same buffer at a concentration of $10 \%(\mathrm{w} / \mathrm{v})$, and kept at $0^{\circ} \mathrm{C}$.

For the preparation of bacterial extracts, the above bacterial suspensions were disrupted for $30 \mathrm{~s}$ at $0^{\circ} \mathrm{C}$ by a sonic oscillator (Heat Systems Co., Plain View, New York, U.S.A., Model W-I85-C).

Assays. Cytochromes $b_{1}$ and $a_{2}$ were measured in bacterial extracts from dithionitereduced minus oxidized difference spectra by using the extinction coefficients given by Jones \& Redfearn (I966). The total iron content of intact and washed bacteria was measured by the method of King, Nickel \& Jensen (I964). Non-haem iron was calculated as the difference between total iron and haem iron (determined from the total cytochrome content). The succinate dehydrogenase activity of bacterial extracts was determined at $22{ }^{\circ} \mathrm{C}$ as described previously (Kim \& Bragg, I97I).

Succinate oxidase was determined as follows: bacterial extract $(0.5 \mathrm{ml})$ and $\mathrm{O} . \mathrm{I} \mathrm{M}-\mathrm{Na}_{2}$ succinate $(0.5 \mathrm{ml})$ were pre-incubated at $37^{\circ} \mathrm{C}$ for $10 \mathrm{~min}$. A sample $(0.2 \mathrm{ml})$ of this mixture was added to $0 . \mathrm{I}$ M-potassium phosphate buffer, $\mathrm{pH} 7.5(5 \mathrm{ml})$ contained in the cuvette of an oxygen monitor (Yellow Springs Instrument Co., Model 55) equipped with a Clark electrode and connected to a linear recorder. Oxygen consumption was measured at $37^{\circ} \mathrm{C}$ after addition of $\mathrm{M}-\mathrm{Na}_{2}$ succinate (O. $\mathrm{I} \mathrm{ml}$ ).

NADH oxidase was measured spectrophotometrically. The change in absorbance at $340 \mathrm{~nm}$ was measured after addition of bacterial extract $(0.05 \mathrm{ml})$ to $0 . \mathrm{I}$ M-potassium phosphate buffer, $\mathrm{pH} 7.5(2.0 \mathrm{ml})$ containing $0.3 \mathrm{~mm}-\mathrm{NADH}$. The reaction was carried out at $22^{\circ} \mathrm{C}$.

The stimulation of respiration by 2,4-dibromophenol or silver nitrate was measured at $22^{\circ} \mathrm{C}$ by means of an oxygraph (Gilson Medical Electronics, Middleton, Wisconsin, U.S.A.) equipped with a Clark oxygen electrode. The cuvette contained o.I M-tris-HCl buffer, $\mathrm{pH} 7.5(3.9 \mathrm{ml})$, bacterial suspension $(0.04 \mathrm{ml})$, and $\mathrm{M}$ glucose $(0.02 \mathrm{ml})$. When the rate of oxygen consumption had been established, O.I M-2,4-dibromophenol was added to 


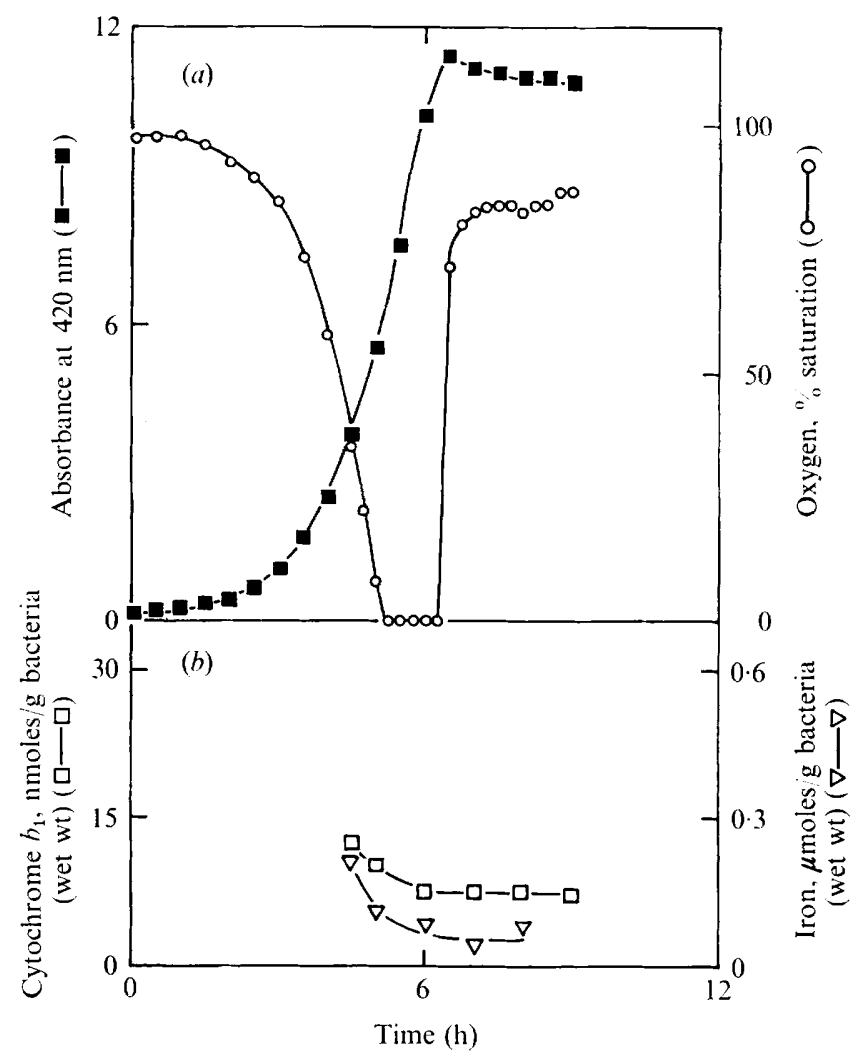

Fig. I. Growth of Escherichia coli in glucose medium unsupplemented with ferric citrate. (a) Variation of growth and oxygen level in the medium. Oxygen level is expressed as \% saturation. (b) Non-haem iron and cytochrome $b_{1}$ levels in bacteria harvested at the indicated times. The concentrations of these components are expressed as $\mu \mathrm{g}$ atoms or nmoles/g bacteria (wet wt), respectively.

give a final concentration of 50 or $130 \mu \mathrm{M}$, and the new rate of oxygen uptake measured. In the experiments with $\mathrm{AgNO}_{3}$ the concentrations used are given in the appropriate legends.

An approximate measurement of the efficiency with which the bacterial culture converted $\mathrm{Na}_{2}$ succinate to bacterial mass was obtained by calculating the increase in absorbancy of the culture at $420 \mathrm{~nm}$ relative to the increase in $\mathrm{pH}$ due to $\mathrm{NaOH}$ produced by utilization of succinate. Since the change in $\mathrm{pH}$ was kept small (0.04 to 0.15 unit), it was proportional to the amount of succinate oxidized. 'Efficiency', is defined as the change in the absorbancy of the culture at $420 \mathrm{~nm}$ during a time interval (generally $30 \mathrm{~min}$ ) divided by the change in the $\mathrm{pH}$ of the culture during the same time interval.

\section{RESULTS}

Growth and oxygen utilization on an iron-limited medium. The change in concentration of oxygen in the medium which occurred during growth of Escherichia coli in a glucosecontaining medium is shown in Fig. I. During the exponential phases of growth the culture maintained the concentration of oxygen in the medium at close to zero. In contrast (Fig. 2), bacteria growing in succinate medium maintained the oxygen concentration of the medium 


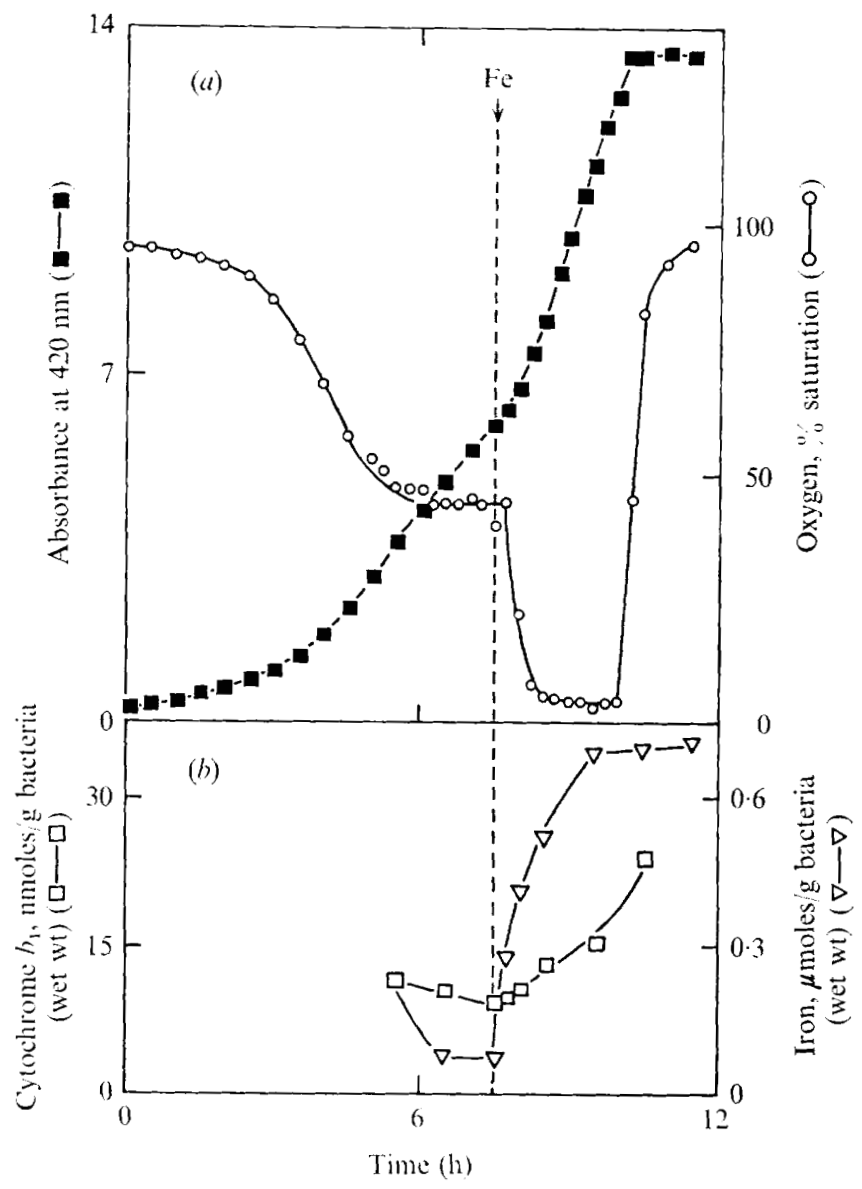

Fig. 2. Growth of Escherichia coli in succinate medium unsupplemented with ferric citrate. At the arrow ferric citrate was added to a final concentration of $6 \mu \mathrm{M}$. (a) Variation of growth and oxygen level in the medium. Oxygen level is expressed as \% saturation. (b) Non-haem iron and cytochrome $b_{1}$ levels in bacteria harvested at the indicated times. The leveis of these components are expressed as $\mu \mathrm{g}$ atoms or nmoles/g bacteria (wet wt), respectively.

at about $45 \%$ saturation. The exact value for this 'plateau' level varied between experiments. To confirm that the concentration of oxygen at the plateau was not an instrumental artifact, aeration of the culture was stopped, the oxygen level fell to zero. A similar result was obtained by gassing the culture with nitrogen or by adding glucose. If the aeration was restarted then the oxygen concentration returned slowly to its former plateau value. The plateau was maintained with little change until all of the succinate had been utilized, at which point the oxygen level returned to saturation. Identical patterns of response were obtained with $E$. coli B and $E$. coli B-SGI.

The rate of oxygen utilization by the entire culture must have remained constant because during the plateau the bacterial mass increased three-fold. This indicated that the rate of oxygen uptake per unit of bacterial mass declined during the period of the plateau. Thus, respiration must have been limited in the bacteria by the presence of an inadequate amount of iron (Fig. 2). Addition of $6 \mu \mathrm{M}$-ferric citrate to the 'iron-deficient bacteria' resulted, after a lag of $\mathrm{I} 5 \mathrm{~min}$, in a stimulation of the rate of oxygen utilization and the oxygen 


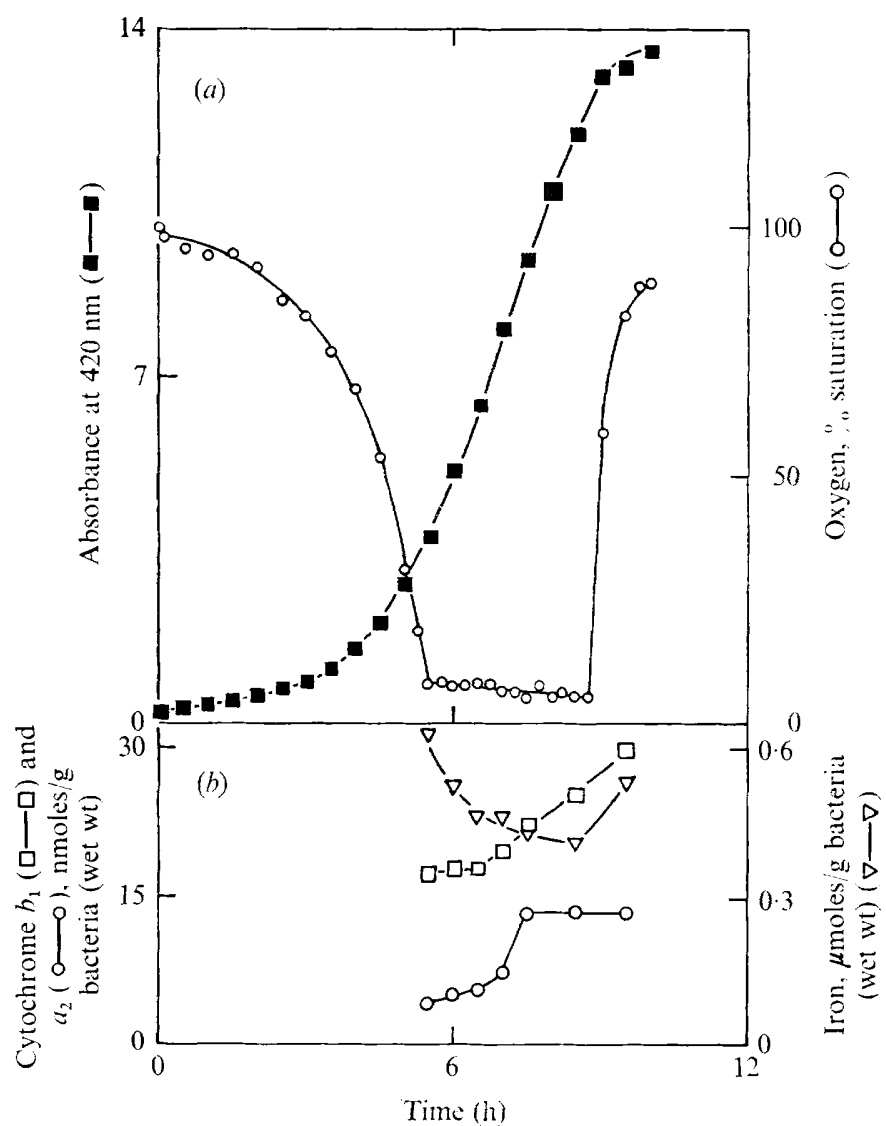

Fig. 3. Growth of Escherichia coli in succinate medium containing $6 \mu \mathrm{M}$-ferric citrate. (a) Variation of growth and oxygen level in the medium. Oxygen level is expressed as \% saturation. (b) Nonhaem iron and cytochrome $b_{1}$ and $a_{2}$ levels in bacteria harvested at the indicated times. The levels of these components are expressed as $\mu \mathrm{g}$ atoms or nmoles/g bacteria (wet wt), respectively.

concentration of the culture fell almost to zero. Replacement of ferric citrate by $6 \mu \mathrm{M}$ sodium citrate did not stimulate oxygen utilization. When the cultures were grown under nitrogen-limited conditions, in the presence of $0 . \mathrm{I} \%$ instead of $0.3 \%\left(\mathrm{NH}_{4}\right)_{2} \mathrm{SO}_{4}$, addition of ferric citrate did not stimulate respiration. Subsequent addition of $\left(\mathrm{NH}_{4}\right)_{2} \mathrm{SO}_{4}$ resulted in stimulation of respiration after a $15 \mathrm{~min}$ lag. These results suggested that protein synthesis was required for respiration to be stimulated by the addition of iron. This factor is at present being studied.

Growth in glucose medium was exponential when the substrate was not limiting (Fig. I), but that in succinate medium became linear when the plateau level of oxygen was reached. Addition of ferric citrate to the culture containing succinate resulted in a stimulation of growth (Fig. 2).

When the culture medium had been initially supplemented with $6 \mu \mathrm{M}$-ferric citrate ('iron-sufficient bacteria') a plateau level of oxygen in the medium was obtained but this was close to zero oxygen (Fig. 3). The rate of increase of bacterial mass (2.83 absorbance units/h) was faster than with iron-deficient bacteria growing in succinate medium (I.I5 absorbance units/h) and was close to that achieved by iron-deficient bacteria which had been 
subsequently supplemented with ferric citrate (2.95 absorbance units/h). That the plateau level of oxygen was close to, but not actually, zero in the iron-supplemented culture may be because this concentration of oxygen was close to the $K_{m}$ for oxygen of the oxidase in the succinate-oxidase chain (White 1962).

Effect of iron limitation on the respiratory chain. The variation in the concentrations of cytochromes and non-haem iron in iron-deficient cultures with glucose and succinate as sources of carbon, and in iron-sufficient cultures in succinate medium, are shown in the lower portions of Fig. I to 3. Under iron-deficient conditions, in the presence of either carbon source the concentration of non-haem iron and cytochrome $b_{1}$ per unit of bacterial mass declined during the period of cultivation. The largest change occurred in the concentration of non-haem iron. In some experiments (results not shown) when succinate was the source of carbon, non-haem iron was not detectable in the plateau region. In iron-sufficient cultures growing in succinate medium there was no change in the concentration of cytochrome during exponential growth. Although the level of non-haem iron decreased in iron-sufficient bacteria the percentage decrease was always much less than in iron-deficient bacteria.

The concentration of cytochromes $b_{1}$ and $a_{2}$ per bacterium increased towards the end of the exponential phase of growth in an iron-sufficient, succinate medium (Fig. 3). The redox potential of the culture was $230 \mathrm{mV}$ when the concentration of the cytochromes began to increase. Formation of cytochrome $a_{2}$ was complete when the redox potential was $210 \mathrm{mV}$. Cytochrome $b_{1}$ formation was still occurring when the redox potential of the culture was I $80 \mathrm{mV}$. Wimpenny \& Necklen (I97I) found that both cytochromes $a_{2}$ and $b_{1}$ were formed maximally when the redox potential of a culture of Escherichia coli growing on a tryptonesalts-glucose medium was $100 \mathrm{mV}$.

Addition of $6 \mu \mathrm{M}$-ferric citrate to iron-deficient cultures growing in succinate medium resulted in an increase in the concentrations in the bacteria of both cytochrome $b_{1}$ and non-haem iron (Fig. 2). Concentration of non-haem iron increased more rapidly than that of the cytochrome. Moreover, the level of non-haem iron had increased sixfold to about one-half of its final value when the stimulation in growth and in respiration commenced. At this point cytochrome $b_{1}$ had increased by about $12 \%$; subsequently it increased to within $8 \mathrm{I} \%$ of the concentration found in iron-sufficient bacteria. The final level of nonhaem iron in supplemented bacteria $(690 \mathrm{ng}$ atoms/g) was greater than that in iron-sufficient bacteria ( 535 to $622 \mathrm{ng}$ atoms/g). These results suggest that the increase in the concentration of non-haem iron rather than of cytochrome was responsible for the initial stimulation of respiration and of growth.

The variation in the activity of succinate dehydrogenase, $\mathrm{NADH}$ and succinate oxidases, and in the level of cytochrome $b_{1}$, during the course of an experiment identical to that shown in Fig. 2 is shown in Table I. There was an increase in the values of all these parameters following addition of ferric citrate to the culture. Succinate oxidase increased at a significantly faster rate than did the other three activities. Since the concentration of succinate oxidase increased at a faster rate than that of both cytochrome $b_{1}$ and succinate dehydrogenase, it was unlikely that the latter components were rate limiting. Thus, in agreement with the previous results (Fig. 2), the rate of the succinate oxidase chain was probably limited by a non-haem iron component. Such a component is known to be present in this system in Escherichia coli ( $\mathrm{Kim} \&$ Bragg, 197I). However, we cannot eliminate the possibility that iron may influence the synthesis of a component which was not measured.

Effect of iron limitation on energy-coupling. Fig. 4 shows the effect of iron deficiency on the efficiency with which succinate was converted to bacterial mass. Iron deficiency resulted 


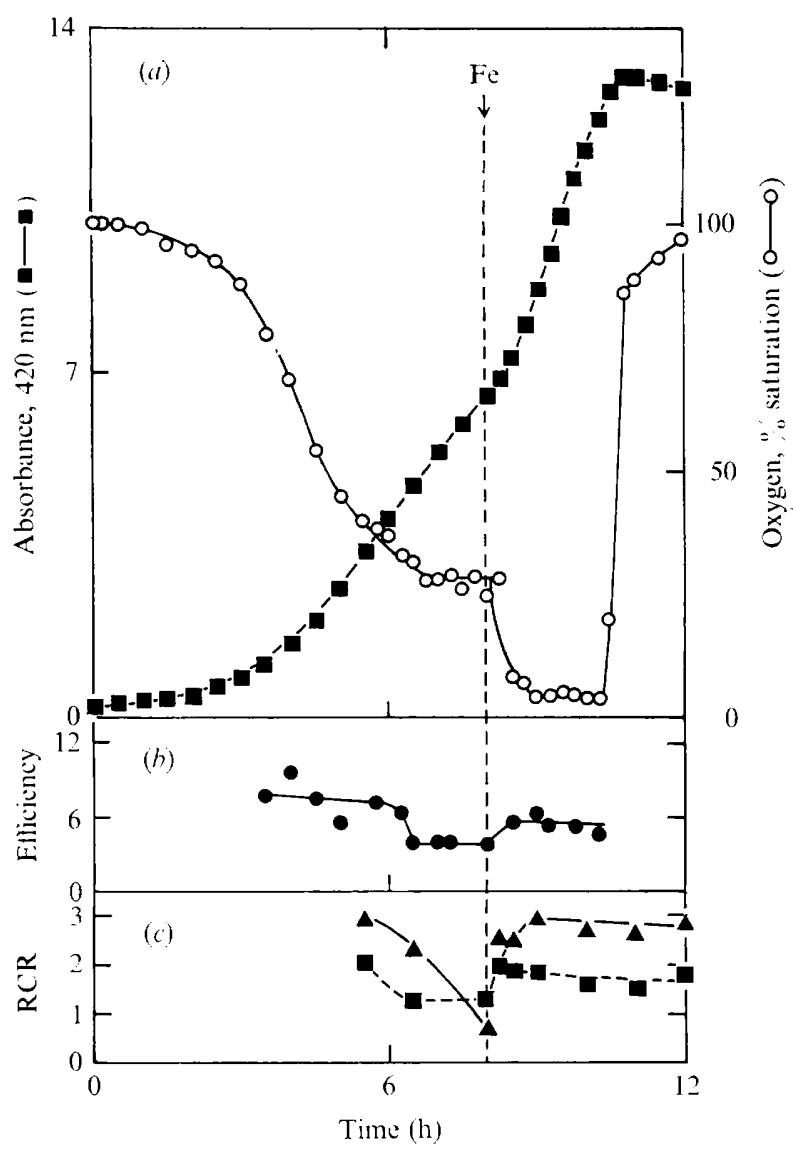

Fig. 4. Growth of Escherichia coli in succinate medium unsupplemented with ferric citrate. At the arrow ferric citrate was added to a final concentration of $6 \mu \mathrm{M}$. (a) Variation of growth and oxygen level in the medium. Oxygen level is expressed as \% saturation. (b) Variation in efficiency of conversion of succinate to bacterial mass. Efficiency is expressed in arbitrary units. (c) Variation in respiratory control ratio (RCR) measured on washed bacterial suspensions using $0.05 \mathrm{mM}(\square-\square)$ or $0.13 \mathrm{mM}(\mathbf{\Delta}-\mathbf{\Delta})$ 2,4-dibromophenol.

Table I. Enzyme activities in extracts of iron-limited succinate-grown bacteria after addition of $6 \mu \mathrm{M}-$ ferric citrate

The experiment was similar to that shown in Fig. 2. Samples were removed at the intervals indicated, sonicated, and assayed for enzyme activity as described in Methods.

\begin{tabular}{|c|c|c|c|c|c|c|c|c|}
\hline $\begin{array}{l}\text { Time }(\mathrm{h}) \text { after } \\
\text { addition of } \mathrm{Fe}^{3+}\end{array}$ & $\begin{array}{c}\text { Cytochrome } \\
b_{1}^{*}\end{array}$ & $\%$ & $\begin{array}{c}\text { NADH } \\
\text { oxidaset }\end{array}$ & $\%$ & $\begin{array}{l}\text { Succinate } \\
\text { oxidase }\end{array}$ & $\%$ & $\begin{array}{c}\text { Succinate } \\
\text { dehydrogenase } \dagger\end{array}$ & $\%$ \\
\hline 0 & 9.7 & 100 & 10.2 & 100 & $4 \mathrm{I} \cdot 4$ & 100 & $27 \cdot 2$ & 100 \\
\hline 0.25 & $8 \cdot 8$ & $9 \mathrm{I}$ & 10.8 & I06 & $46 \cdot 3$ & I I 2 & 25.5 & 94 \\
\hline 0.5 & $9 \cdot 4$ & 97 & I I 8 & I 16 & 65.3 & I 58 & 31.9 & I I 7 \\
\hline I. O & II 2 & I I 6 & 13.9 & I36 & $70 \cdot 7$ & 171 & 35.0 & I 39 \\
\hline 2.0 & 15.6 & I6I & I 6.1 & 158 & 87.8 & 212 & $49 \cdot 7$ & 183 \\
\hline 4.0 & 17.5 & 180 & 16.7 & 164 & $84^{\cdot 2}$ & 203 & 57.8 & 212 \\
\hline
\end{tabular}

* Values expressed as nmoles/g bacteria (wet wt).

$\dagger$ Values expressed as $\mu$ moles substrate oxidized $/ \mathrm{min} / \mathrm{g}$ bacteria at $22^{\circ} \mathrm{C}$.

† Values expressed as $\mu$ moles substrate oxidized $/ \mathrm{min} / \mathrm{g}$ bacteria at $37^{\circ} \mathrm{C}$. 


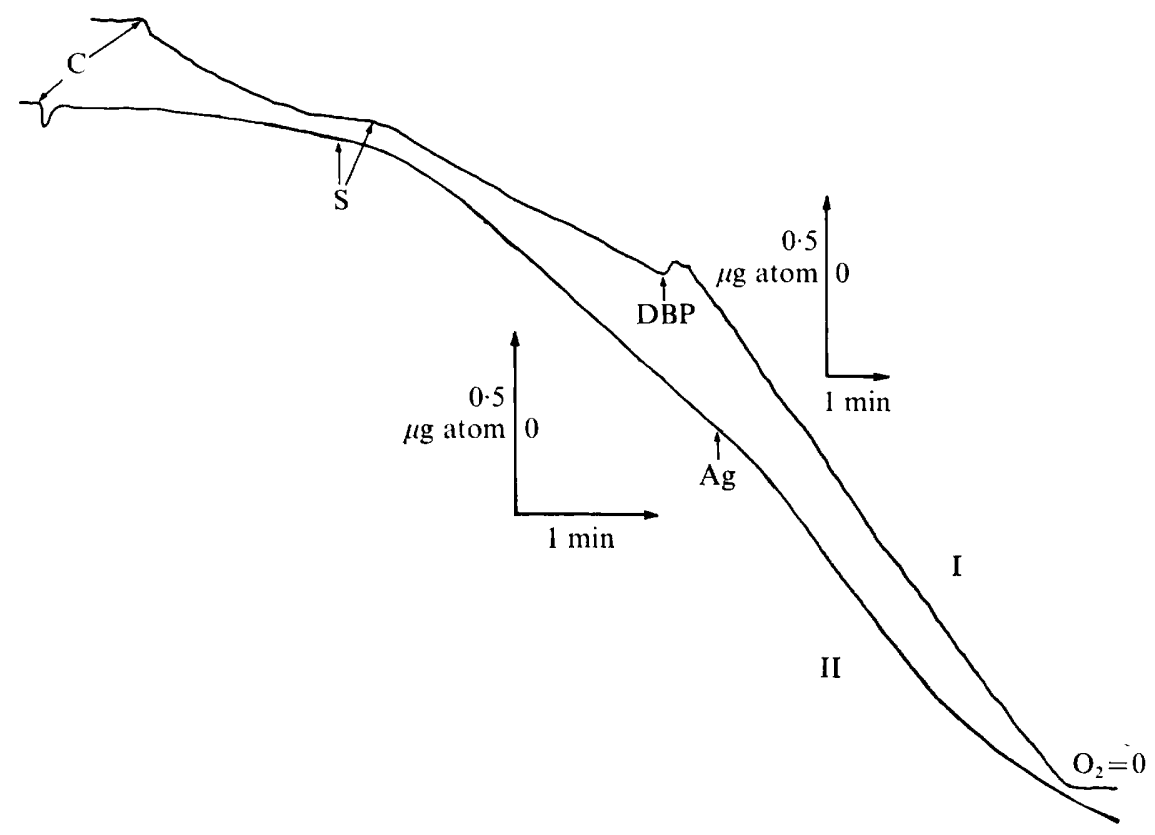

Fig. 5. Oxygen electrode traces of the effect of 2,4-dibromophenol and silver ions on oxygen uptake by intact Escherichia coli. Oxygen uptake was measured at $22^{\circ} \mathrm{C}$ in a suspension of bacteria grown in succinate medium. I. The assay system $(3.90 \mathrm{ml})$ contained $100 \mathrm{~mm}$-tris- $\mathrm{HCl}$ buffer, $\mathrm{pH} 7.5$. At the indicated times $0.04 \mathrm{ml}$ of bacterial suspension (C), $0.02 \mathrm{ml} \mathrm{M}$-glucose (S) and $0.05 \mathrm{ml}$ io mM-2,4-dibromophenol (in methanol) (DBP) were added. II. The assay system (3.90 ml) contained $95 \mathrm{~mm}$-tris-HCl buffer, $\mathrm{pH} 7 \cdot 5$. At the indicated times $0.2 \mathrm{ml}$ of bacterial suspension (C), $0.02 \mathrm{ml}$ $\mathrm{M}$-glucose (S) and $0.01 \mathrm{ml}$ Io $\mathrm{mM}^{-\mathrm{AgNO}_{3}}(\mathrm{Ag})$ were added.

in a decreased efficiency of energy conservation. Full efficiency returned after the addition of iron.

Hempfling (1970) has shown that respiration of whole bacteria of Escherichia coli, when oxidizing glucose, was stimulated by the addition of 2,4-dibromophenol only when all three sites of oxidative phosphorylation are functional. The 'respiratory-control ratio' is defined as the rate of respiration in the presence of dibromophenol relative to the rate of respiration in the absence of this compound (Fig. 5). This ratio decreased to about $\mathrm{I} \cdot \mathrm{O}$ under conditions of progressive iron deficiency in a culture growing on succinate (Fig. 4). After addition of $6 \mu \mathrm{M}$-ferric citrate to the culture there was a threefold increase in the respiratorycontrol ratio. The rate of recoupling (increase in respiratory-control ratio) after addition of ferric citrate was faster than the rate of increase in the activity of the respiratory chain, and more closely followed the kinetics of non-haem iron.

There was an initial stimulatory effect on respiration after the addition of $\mathrm{AgNO}_{3}$ to Escherichia coli (Fig. 5), which was followed by an inhibition. The stimulation by silver ions was greater in bacteria harvested subsequent to iron supplementation than in bacteria harvested from iron-deficient conditions (Table 2). This result is of interest in light of the known reaction of silver ions with sulphydryl groups and of the association of sulphydryl groups with non-haem iron proteins (Palmer \& Brintzinger, I972). 
Table 2. Effect of silver nitrate on respiration in iron-deficient and iron-supplemented Escherichia coli

\begin{tabular}{|c|c|c|}
\hline \multirow{2}{*}{$\begin{array}{c}\text { Silver } \\
\left(\mu_{\mathrm{M}}\right)\end{array}$} & \multicolumn{2}{|c|}{ Relative rate* } \\
\hline & Iron-deficient & Iron-sufficient \\
\hline 2.5 & $\mathrm{I} \cdot 55$ & $\mathrm{I} \cdot 33$ \\
\hline 5.0 & $1 \cdot 80$ & $\mathrm{I} \cdot 74$ \\
\hline 12.5 & $\mathrm{I} \cdot 84$ & $2 \cdot 45$ \\
\hline 25 & $1 \cdot 64$ & $2 \cdot 50$ \\
\hline 50 & $\mathrm{I} \cdot 86$ & 2.80 \\
\hline I 25 & - & $2 \cdot 09$ \\
\hline 250 & I $\cdot 28$ & $2 \cdot 15$ \\
\hline
\end{tabular}

* Relative rate is the ratio of the maximum rate of oxygen uptake in the presence of $\mathrm{AgNO}_{3}$ to the rate of oxygen uptake immediately before the addition of $\mathrm{AgNO}_{3}$.

\section{DISCUSSION}

There is little evidence available that iron is involved in energy-coupling in bacterial systems. Oxidative phosphorylation has been shown to be uncoupled by chelating agents in Azotobacter vinelandii (Jones, Ackrell \& Erickson, 1972), Streptococcus faecalis (Faust \& Vandemark, 1970), Escherichia coli (Kashket \& Brodie, 1963), and Mycobacterium phlei (Kurup \& Brodie, 1967). The data in the present paper support the hypothesis that nonhaem iron is involved in energy-coupling in E. coli.

The greater sensitivity to iron deficiency of the growth and respiration of the culture grown in succinate medium compared with that grown in glucose medium is in accordance with the hypothesis that iron limitation affects the respiratory chain and/or coupled energy production because fermentation would provide sufficient energy during growth in the presence of glucose. Lower levels of cytochrome $b_{1}$, and succinate and NADH oxidase activities in iron-deficient as compared to iron-supplemented cells indicate that a direct effect on the respiratory chain must have occurred, as has been observed also in iron-deficient Corynebacterium diphtheriae (Righelato, I969) and Mycobacterium smegmatis (Winder \& O'Hara, I964). An effect on respiratory chain-linked energy production, in addition to that caused by lower respiratory chain activity, is suggested by (i) the efficiency of production of bacterial mass, in succinate medium, which decreased during depletion of iron but which was restored on supplementation of the culture with ferric citrate, (ii) the decrease in the respiratory-control ratio during iron deficiency and the rapid recovery after addition of iron. The rate of restoration of the latter property on addition of ferric citrate to the irondeficient bacteria occurred more rapidly than the restoration of full oxidase activity and of cytochrome $b_{1}$, and was comparable to the rate of increase in the concentration of non-haem iron in the bacteria. These results are compatible with the hypothesis that non-haem iron has a role in energy conservation linked to the respiratory chain of Escherichia coli.

A similar situation to the above has been reported for Candida utilis where iron deficiency gave yeast which lacked oxidative phosphorylation at site I (Clegg \& Garland, 197I). This yeast also had lower concentrations of cytochromes (Ohnishi, Schleyer \& Chance, 1969; Clegg \& Garland, 197I), although the oxidation of NADH was not affected (Clegg \& Garland, 1971). Our experiments do not indicate whether energy-coupling was affected at one or at all sites in iron-limited cells of Escherichia coli. However, there is at present no technique which will permit the measurement of the individual sites of oxidative phosphorylation in E. coli. 
This work was supported by a grant from the Medical Research Council of Canada, and by the award of a Medical Research Council Studentship to D. J. Rainnie.

\section{REFERENCES}

CleGG, R. A. \& Garland, P. B. (I97I). Nonhaem iron and the dissociation of piericidin A sensitivity from site I energy conservation in mitochondria from Torulopsis utilis. Biochemical Journal 124, I35-I 54.

Faust, P. J. \& Vandemark, P. J. (1970). Phosphorylation coupled to NADH oxidation with fumarate in Streptococcus faecalis 10Cl. Archives of Biochemistry and Biophysics 137, 392-398.

Fewson, C. A. \& Nicholas, D. J. D. (I96r $a$ ). Respiratory enzymes in Micrococcus denitrificans. Biochimica et biophysica acta 48, 208-2I0.

Fewson, C. A. \& Nicholas, D. J. D. (I96I $b$ ). Nitrate reductase from Pseudomonas aeruginosa. Biochimica et biophysica acta 49, 335-349.

Gel'man, N. S., Lukoyanova, M. A. \& OstrovskiI, D. N. (1967). Respiration and Phosphorylation of Bacteria. New York: Plenum Press.

HAROLD, F. M. (1972). Conservation and transformation of energy by bacterial membranes. Bacteriological Reviews 36, $172-230$.

HeMPfLING, W. P. (1970). Repression of oxidative phosphorylation in Escherichia coli by growth in glucose and other carbohydrates. Biochemical and Biophysical Research Communications 4r, 9-I5.

Imai, K., Asano, A. \& SATo, R. (1968). Oxidative phosphorylation in Micrococcus denitrificans. V. Effects of iron deficiency on respiratory components and oxidative phosphorylation. Journal of Biochemistry 63, 219-225.

John, P. \& HamLton, W. A. (1971). Release of respiratory control in particles from Micrococcus denitrificans by ion-translocating antibiotics. European Journal of Biochemistry 23, 528-532.

JONES, C. W. \& REDFEARN, E. R. (1966). Electron transport in Azotobacter vinelandii. Biochimica et biophysica acta II3, 467-48I.

Jones, C. W., Ackrell, B. A. C. \& Erickson, S. K. (197I). Respiratory control in Azotobacter vinelandii membranes. Biochimica et biophysica acta 245, 54-62.

Jones, C. W., ACKRell, B. A. C. \& ERICKSON, S. K. (I972). The involvement of iron in the respiratory chain of Azotobacter vinelandii. Biochemical Journal 127, $74 \mathrm{P}$.

KASHKET, E. R. \& BRODIE, A. F. (I963). Oxidative phosphorylation in fractionated bacterial systems. VIII. Role of particulate and soluble fractions from Escherichia coli. Biochimica et biophysica acta 78, 52-65.

KIM, I. C. \& BRAGG, P. D. (197I). Properties of nonhaem iron in a cell envelope fraction from Escherichia coli. Journal of Bacteriology ro7, 664-670.

KING, T. E., Nickel, K. S. \& Jensen, D. R. (I964). Iron, copper, cytochrome and lipid contents of heart muscle preparation and heart mitochondria. Journal of Biological Chemistry 239, 1989-1994.

KURUP, C. K. R. \& BRoDIE, A. F. (I967). Oxidative phosphorylation in fractionated bacterial systems. XXV. Studies on the involvement of metal in Mycobacterium phlei. Journal of Biological Chemistry 242, 197-203.

Ohnishi, T., Schleyer, H. \& Chance, B. (1969). Studies on nonhaem iron proteins and the piericidin A binding site of submitochondrial particles from Candida utilis cells grown in media of varying iron concentrations. Biochemical and Biophysical Research Communications 36, 487-493.

Palmer, G. \& Brintzinger, H. (1972). The properties of nonporphyrin bound metals functional in biological oxidation reduction reactions. In Electron and Coupled Energy Transfer in Biological Systems, pp. 379-476. Edited by T. E. King and M. Klingenberg. New York: Marcel Dekker.

RADCliffe, B. C. \& Nicholas, D. J. D. (1970). Some properties of a nitrate reductase from Pseudomonas denitrificans. Biochimica et biophysica acta 205, 273-387.

Righelato, R. C. (1969). The distribution of iron in iron-deficient toxin-synthesizing and in excess-iron non-toxin-synthesizing Corynebacterium diphtheriae. Journal of General Microbiology 58, 4I I-419.

WHITE, D. C. (1962). Factors affecting the affinity for oxygen of cytochrome oxidase in Hemophilus parainfluenzae. Journal of Biological Chemistry 238, 3757-376r.

WimpenNy, J. W. T. \& NeCKLEN, D. K. (I97I). The redox environment and microbiol physiology. I. The transition from anaerobiosis to aerobiosis in continuous cultures of facultative anaerobes. Biochimica et biophysica acta 253, 352-359.

WINDER, F. G. \& O'HARA, C. (I964). Effects of iron deficiency and zinc deficiency on the activities of some enzymes in Mycobacterium smegmatis. Biochemical Journal 9o, 122-126. 